\title{
ROLE OF PLACENTAL LOCALISATION IN PREDICTION OF PREGNANCY INDUCED HYPERTENSION
}

\author{
Saudamini Amit Naik1, Amit Sharad Naik2, Vikram Ashok Phadol ${ }^{3}$
}

${ }^{1}$ Assistant Professor, Department of Obstetrics and Gynaecology, SMBT Institute of Medical Sciences and Research Centre. ${ }^{2}$ Assistant Professor, Department of Obstetrics and Gynaecology, SMBT Institute of Medical Sciences and Research Centre. ${ }^{3}$ Assistant Professor, Department of Obstetrics and Gynaecology, SMBT Institute of Medical Sciences and Research Centre.

ABSTRACT
BACKGROUND
Pregnancy-induced hypertension is one of the leading causes of foetal and maternal morbidity and mortality worldwide. In our
country, the prevalence of the disease is $5-15 \%$ and perinatal death rate due to PIH is $20 \%$. Early detection becomes very essential
as the disease is detected in advanced stages most of the times. Hence, screening for the prediction of PIH becomes necessary for
improving maternal and foetal outcome.
Aims- To evaluate the relationship between placental location and occurrence of PIH. To determine whether placental location can
be used as a screening test for detection of PIH and to study maternal and foetal outcome in these patients.

\section{MATERIALS AND METHODS}

Primigravidae with singleton pregnancy, without any medical disorder were considered for the study and were subjected to ultrasound examination to scan for gestational age, placental localisation- Central or lateral, amount of liquor amnii, congenital anomalies. The location of placenta was determined around or more than 24 weeks of gestation with real time ultrasound and repeat ultrasound was done in some patients at a later gestation to confirm the placental location. All patients with unilateral placenta on scan were followed up to delivery and the early detection of PIH reported, also the maternal and neonatal outcome was studied at delivery. Measurements were obtained \& reported. The relationship between laterality of placenta and occurrence of PIH noted and discussed.

Statistical Analysis Used- Statistical analysis was done using percentages and Chi-square test.

Settings and Design- This was a prospective study conducted over a period of 6 months from September 2015 to February 2016 in the Department of Obstetrics and Gynaecology, SMBT Institute of Medical Sciences, Dhamangaon, Nasik.

\section{RESULTS}

The present study showed the incidence of PIH in primigravidae to be $15.24 \%$ and incidence of lateral placentation in primigravidae being $15.8 \%$. Our study also shows that 63 out of 83 primigravidae with lateral placenta developed PIH and 17 out of 425 primigravidae without lateral placenta developed PIH. The sensitivity and specificity of our study being $75.9 \%$ and $96.15 \%$ respectively.

\section{CONCLUSION}

Evidence of lateral placenta on ultrasonography is a very useful addition to our armamentarium of antepartum testing for prediction of PIH and its management. Placental localisation has a definite potential to serve as a simple, non-invasive screening test for prediction of PIH.

\section{KEYWORDS}

Placenta, Pregnancy-induced Hypertension.

HOW TO CITE THIS ARTICLE: Naik SN, Naik AS, Phadol VA. Role of placental localisation in prediction of pregnancy induced hypertension. J. Evolution Med. Dent. Sci. 2017;6(20):1600-1602, DOI: 10.14260/Jemds/2017/351

\section{BACKGROUND}

Pregnancy-induced hypertension (PIH) still remains one of the leading causes of foetal and maternal morbidity and mortality. In our country, the prevalence of the disease is 5$15 \%{ }^{1}$ and perinatal death rate due to PIH is $20 \%$. Early detection becomes very essential as the disease is detected in advanced stages most of the times. Hence, screening for the prediction of PIH becomes necessary for improving maternal and foetal outcome.

Financial or Other, Competing Interest: None.

Submission 31-01-2017, Peer Review 24-02-2017,

Acceptance 01-03-2017, Published 09-03-2017.

Corresponding Author:

Dr. Amit Sharad Naik,

Naik Hospital, Kathe Galli,

Opp. Saras Vihar Society,

Dwarka, Nashik-422011, Maharashtra.

E-mail: drnaikamit@gmail.com

DOI: $10.14260 /$ jemds $/ 2017 / 351$

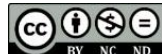

Screening at its earliest stage in substantial segment of the population is a logical extension of the role of preventive medicine. An ideal screening test should be simple, safe, noninvasive, inexpensive, reliable, easy to perform, readily interpretable. A myriad of potential screening tests for prediction of PIH have been advocated. But till date no ideal screening test for prediction of PIH is available. And the search is still going on. Introduction of ultrasound to Obstetrics by Ian Donald ${ }^{2}$ et al in 1958 has been a major milestone in the realm of antenatal care. It is an ideal screening test for various conditions. Schulman ${ }^{3}$ et al in 1986 used ultrasound to determine association between placental location and PIH. He found that unilateral placenta was associated with increased incidence of PIH. The present study aims to review the screening potential of placental location with the help of ultrasound in predicting pregnancy-induced hypertension. 


\section{Aims and Objectives}

To evaluate the relationship between placental location and occurrence of PIH.

To determine whether placental location can be used as a screening test for detection of PIH.

To study maternal and foetal outcome in these patients.

\section{MATERIALS AND METHODS}

The study "Role of Placental Localisation in Prediction of Pregnancy-induced Hypertension." This was a prospective study conducted over a period of 6 months from September 2015 to February 2016 in the Department of Obstetrics and Gynaecology, SMBT Institute of Medical Sciences, Dhamangaon, Nasik. Ultrasonography is being used as a routine investigation for antenatal screening in this institution by using real time ultrasound. Primigravidae with singleton pregnancy, without any medical disorder were considered for the study and were subjected to ultrasound examination to scan the following-

1. Estimation of gestational age.

2. Evaluation of foetal growth parameters.

3. Placental localisation- central or lateral.

4. Amount of liquor amnii.

5. Congenital anomalies.

The location of placenta was determined around or more than 24 weeks of gestation with real time ultrasound, and repeat ultrasound was done in some patients at a later gestation to confirm the placental location. The placenta was classified central when it was equally distributed on the right \& left side irrespectively of the anterior, posterior or fundal position. When $75 \%$ or more mass was on one side of the midline it was classified as unilateral placenta irrespective of the anterior, posterior or fundal position. All patients with unilateral placenta on scan were followed up to delivery and the early detection of PIH reported, also the maternal and neonatal outcome were studied. Measurements were obtained and reported. The relationship between laterality of placenta and occurrence of PIH noted and discussed.

\section{OBSERVATION AND RESULTS}

\section{Important Facts of this Study are-}

\begin{tabular}{|c|c|c|}
\hline 1 & $\begin{array}{l}\text { Total No. of primigravidae delivered during } \\
\text { study period }\end{array}$ & 525 \\
\hline 2 & $\begin{array}{l}\text { Total No. of primigravidae with lateral } \\
\text { placenta }\end{array}$ & 083 \\
\hline 3 & $\begin{array}{l}\text { Total No. of primigravidae with lateral } \\
\text { placenta with PIH }\end{array}$ & 063 \\
\hline 4 & $\begin{array}{l}\text { Total No. of primigravidae with no lateral } \\
\text { placenta with PIH }\end{array}$ & 017 \\
\hline 5 & $\begin{array}{l}\text { Total No. of primigravidae with lateral } \\
\text { placenta with no PIH }\end{array}$ & 020 \\
\hline 6 & $\begin{array}{c}\text { Total No. of primigravidae with no lateral } \\
\text { placenta with no PIH }\end{array}$ & 425 \\
\hline
\end{tabular}

\begin{tabular}{|c|c|c|}
\hline Age & No. of Cases & Percentage \\
\hline$<20$ yrs. & 11 & $17.46 \%$ \\
\hline $21-30$ yrs. & 45 & $71.43 \%$ \\
\hline >31 yrs. & 07 & $11.11 \%$ \\
\hline \multicolumn{3}{|c|}{ Table 1. Analysis of Primigravidae with Lateral Placenta } \\
with PIH \\
\hline
\end{tabular}

Majority of the patients were in the age group of 21-30 years.

\begin{tabular}{|c|c|c|}
\hline GA in weeks & Cases & Percentage \\
\hline$>24-28$ & 21 & $33.33 \%$ \\
\hline $28.1-34$ & 37 & $58.73 \%$ \\
\hline$>34.1$ & 05 & $7.94 \%$ \\
\hline \multicolumn{2}{|c|}{ Table 2. Gestational Age(GA) on Ultrasound Examination } \\
\hline
\end{tabular}

USG was done in gestation > 24 weeks. Repeat USG done in patients where first USG was before 28 weeks.

\begin{tabular}{|c|c|c|}
\hline GA & No. of cases & Percentage \\
\hline$<37$ weeks & 23 & $36.50 \%$ \\
\hline 37.0-40.0 weeks & 33 & $52.38 \%$ \\
\hline$>40.1$ weeks & 07 & $11.11 \%$ \\
\hline \multicolumn{3}{|c|}{ Table 3. Gestational Age (GA) at Detection of PIH } \\
\hline
\end{tabular}

Maximum cases of PIH were detected between 37 to 40 weeks of gestation.

\begin{tabular}{|c|c|c|}
\hline Mode & Cases & Percentage \\
\hline Vaginal & 43 & $68.25 \%$ \\
\hline LSCS & 17 & $26.98 \%$ \\
\hline Instrumentation & 03 & $4.76 \%$ \\
\hline \multicolumn{2}{|c|}{ Table 4. Mode of Delivery } \\
\hline
\end{tabular}

$68.25 \%$ patients delivered vaginally while $26.98 \%$ underwent LSCS and $4.76 \%$ required instrumentation ( 1 forceps and 2 ventouse).

\begin{tabular}{|c|c|c|}
\hline Onset & Cases & Percentage \\
\hline Spontaneous & 56 & $88.89 \%$ \\
\hline Induced & 7 & $11.11 \%$ \\
\hline \multicolumn{3}{|c|}{ Table 5. Type of Delivery } \\
\hline
\end{tabular}

Induction was required in only $11.11 \%$ cases. Indication being severe PIH, postdatism.

\begin{tabular}{|c|c|c|}
\hline GA & Cases & Percentage \\
\hline$<37$ wks. & 17 & $26.98 \%$ \\
\hline $37-40$ wks. & 38 & $60.32 \%$ \\
\hline$>40.1$ wks. & 8 & $12.70 \%$ \\
\hline \multicolumn{2}{|c|}{ Table 6. Gestational Age (GA) at Delivery } \\
\hline
\end{tabular}

Maximum patients delivered between 37-40 weeks' gestation.

\begin{tabular}{|c|c|c|}
\hline Maternal Outcome & Cases & Percentage \\
\hline Mild PIH & 52 & $82.54 \%$ \\
\hline Severe PIH & 10 & $15.87 \%$ \\
\hline Eclampsia & 01 & $1.59 \%$ \\
\hline Other complication & 00 & 00 \\
\hline \multicolumn{2}{|c|}{ Table 7. Maternal Outcome } \\
\hline
\end{tabular}

Majority of patients had mild PIH. Incidence of severe PIH being $15.87 \%$ and that of eclampsia being $1.59 \%$.

\begin{tabular}{|c|c|c|}
\hline Foetal Outcome & Cases & Percentage \\
\hline NICU admissions & 11 & $17.46 \%$ \\
\hline With Mother & 51 & $80.96 \%$ \\
\hline Neonatal death & 01 & $1.59 \%$ \\
\hline SB & 0 & $0 \%$ \\
\hline \multicolumn{2}{|c|}{ Table 8. Foetal Outcome } \\
\hline
\end{tabular}

$17.46 \%$ babies required NICU admission with $1.59 \%$ resulting in adverse perinatal outcome in the form of neonatal death. 


\begin{tabular}{|c|c|c|}
\hline NICU Admission & Cases & Percentage \\
\hline IUGR & 3 & $20 \%$ \\
\hline Preterm & 7 & $50 \%$ \\
\hline MSAF & 1 & $10 \%$ \\
\hline Birth asphyxia & 3 & $20 \%$ \\
\hline \multicolumn{2}{|c|}{ Table 9. NICU Admission } \\
\hline
\end{tabular}

\begin{tabular}{|c|c|c|}
\hline Placental location & Outcome PIH & No PIH \\
\hline Lateral, $\mathrm{n}=83$ & $63(75.09 \%)$ & $20(24.1 \%)$ \\
\hline Central, $\mathrm{n}=442$ & $17(3.84 \%)$ & $425(96.15 \%)$ \\
\hline \multicolumn{3}{|c|}{$\chi^{2}=280.9, \mathrm{p}=0.00001$. Result is highly significant } \\
\hline \multicolumn{3}{|c|}{ Table 10. Relationship between Placental Location and } \\
PIH \\
\hline
\end{tabular}

Following are the Results for Lateral Placenta on Ultrasonography beyond 28 weeks as a Predictor of Pregnancy-induced Hypertension-

- $\quad$ Sensitivity $=75.90 \%$

- $\quad$ Specificity $=96.15 \%$

- $\quad$ Positive predictive value $=78.75 \%$

- $\quad$ Negative predictive value $=91.40 \%$

- $\%$ of age of false negative $=24.10 \%$

- $\%$ of age of false positive $=03.85 \%$

\section{DISCUSSION}

The present study showed the incidence of PIH in primigravidae to be $15.24 \% .{ }^{1}$ This can be explained by the incidence of PIH in our country $\left(10-15 \%^{2}\right)$ and majority of the incidence is found in primigravidae as they are exposed to chorionic villi for the $1^{\text {st }}$ time. Bangal $\mathrm{VB}^{3}$ et al reported the incidence of PIH to be $8.96 \%$ in his study. Our study shows slightly higher incidence due to the fact that our centre being a tertiary referral hospital in a rural area where all high risk cases are referred and other factors like poverty, lack of basic antenatal care facilities, and poor nutrition in rural areas also contribute to the same.

Our study also shows that 63 primigravidae who developed PIH had unilateral placenta, thus giving an incidence of $78.75 \%$ lateral placenta in PIH. These studies are similar to studies carried out by Kofinas et al. ${ }^{4}$ Neetu Singh ${ }^{5}$ in her study stated the incidence to be $62.9 \%$ which is less than that of our study. Tania Kakkar in her study found the overall risk of developing PIH with laterally located placenta to be 5.09 (odds ratio) and 95\% CI 2.40-10.88. The difference was found to be highly significant statistically ( $p=0.00002)$. In PIH due to defective trophoblastic invasion in spiral arteries, there is increase in resistance as shown by increased indices and decreased uteroplacental perfusion on Doppler studies and is associated with IUGR. Kofinas et $\mathrm{al}^{4}$ found that $75 \%$ of the pregnancy complicated with preeclampsia and IUGR had unilaterally located placenta and $25 \%$ had central placenta. The patient with unilateral placenta was more associated with abnormal uterine artery flow velocity waveform than central placenta. Incidence of PIH in unilateral placenta group was more than in central placenta group and was statistically significant $(\mathrm{P}=<.05)$.
The results of the study conducted by us on 83 primigravidae with lateral placenta is comparable to various studies conducted worldwide. Out of 83 patients, 63 developed PIH.

Ultrasonography was done in second trimester ( $>24$ wks. gestation) for placental location and some also had a repeat USG done in third trimester. Patients were followed up to delivery.

$68.25 \%$ had vaginal delivery while $26.98 \%$ underwent LSCS rate and $4.76 \%$ required instrumentation.

Adverse perinatal outcome was encountered in $19.05 \%$. Out of these, $17.46 \%$ were NICU admission for IUGR, meconium aspiration, prematurity \& birth asphyxia. 1 neonatal death was encountered in a baby with mother having eclampsia. The morbidity of babies increased with severity of PIH.

Patients with lateral placenta on ultrasonography were seen to develop PIH in $3^{\text {rd }}$ trimester or intrapartum. Thus, we conclude that detection of lateral placenta in $2^{\text {nd }}$ trimester ultrasonographically is an early indication of forthcoming PIH in $3^{\text {rd }}$ trimester. The sensitivity and specificity of our study were $75.9 \%$ and $96.15 \%$ respectively. We found the overall risk of developing PIH with laterally located placenta to be 78.75 (odds ratio) and 95\% CI 39.16 to 158.36. Data was statistically analysed using Chi-square test, and these findings were found to be statically significant. This clearly indicates that PIH is associated with unilateral placenta. Placental localisation, therefore, has a definite potential to serve as a simple, non-invasive screening test for prediction of PIH.

\section{CONCLUSION}

Evidence of lateral placenta on ultrasonography is a very useful addition to our armamentarium of antepartum testing for prediction of PIH and its management.

\section{REFERENCES}

[1] Sachdeva PD, Patel BG, Bhatt MV. A study of incidence and management of Pregnancy-induced Hypertension in central Gujarat, India. Int J Univ Pharm Life Sci 2011;1:61-70.

[2] Doddamani GB, Doddamani UG. Perinatal outcome in pre-eclampsia: a prospective study. Scholars Journal of Applied Medical Sciences (SJAMS) 2014;2(1C):291-3.

[3] Bangal VB, Giri PA, Mahajan AS. Maternal and foetal outcome in Pregnancy-induced Hypertension: a study from rural tertiary care teaching hospital in India. Int J Biomed Res 2011;2(12):595-9.

[4] Kofinas AD, Penry M, Swain M, et al. Effect of placental laterality on uterine artery resistance and development of preeclampsia and intrauterine growth retardation. AM J Obstet Gynecol 1989;161(6 Pt 1):1536-9.

[5] Singh N, Gupta R, Pandey K, et al. To study second trimester placental location as a predictor of adverse pregnancy outcome. Int J Reprod Contracept Obstet Gynecol 2016;5(5):1414-7. 